\title{
Secondary Glaucoma: Treatable Visual Threat in Uveitis?
}

\author{
Authors \\ Dr Sanjoy Chowdhury MS.DO.DNB ${ }^{1}$ Dr Hitesh Patel ${ }^{2}$, Dr Pratik Bhosale ${ }^{3}$, \\ Dr Kavita Prasad ${ }^{4}$, Nilanjan Chowdhury ${ }^{5}$ \\ ${ }^{1}$ Joint Director (Medical \& Health Services, SAIL/BGH \\ 4C/3020 Bokaro Steel City, Jharkhand_827004 \\ ${ }^{2,3,4}$ DNB Residents, Bokaro General Hospital, Jharkhand, India \\ ${ }^{5}$ MBBS (Final yr, Sikkim Manipal Institute of Medical Sciences, Gangtok, India \\ Email:drsanjoybokaro@rediffmail.com
}

\begin{abstract}
Background: Secondary Glaucoma, due to disease and drugs is an important cause of morbidity in uveitis. Purpose: To evaluate prevalence of secondary glaucoma $(S G)$ in uveitis with different treatment regimen Methods: Randomised prospective hospital based study of uveitis from 2007-2012.Baseline IOP; Field and optic nerve head photographs were recorded. Three groups were randomised: 1.topical steroid 2.Systemic steroid $+g r$ 1, 3.Topical synthetic steroids, cycloplegic and periorbital triamcinolone injection. IOP more than $22 \mathrm{~mm} / 4 \mathrm{~mm}$ increase from baseline is marker.

Results: Study included 1254 cases of uveitis (prevalence rate 63/100000; Bokaro: $n$ 2061918, census 2011) with 82 secondary glaucoma, $70 \%$ in anterior uveitis. During treatment, SG was maximum (80\%) in first group and least (5\%) with synthetic steroid combined with periorbital triamcinolone. Multi variety analysis shows synthetic steroid and periorbital triamcinolone has least association with SG. Macular oedema was more in SG which improved with low dose acetazolamide. $25 \%$ cases had progressive visual field loss.

Conclusion: $S G$ is an underappreciated visual threat in uveitis which can be modulated effectively with newer steroids and low dose acetazolamide
\end{abstract}

\section{Introduction}

Despite its relative rarity, uveitis is the third leading cause of preventable blindness worldwide $^{[1,2]}$. Glaucoma associated with uveitis is one of the most serious complications of intraocular inflammation and most overlooked reason for visual loss. ${ }^{[3]}$.Over 2 million people worldwide are thought to have uveitis. Despite significant advances in therapeutics, the prevalence of blindness secondary to uveitis has not been reduced in the past 30 years. In the largest population-based study in the United
States, the incidence of uveitis was approximately 3 times that of previous estimates and increased with the increasing age of patients. Women had a higher prevalence of uveitis than men, and the largest differences were in older age groups. Unless interventions improve, about $10 \%$ of patients with uveitis will be blinded by it. Epidemiological studies in the United States suggest that this underestimates the risk by as much as 4- to 5-fold. The sight-threatening complications of uveitis include damage to the retina and glaucoma. 
Patients with uveitis have an increased risk of developing glaucoma not only because of the uveitis, but also as a side effect of the use of corticosteroids, the mainstay of treatment. The association between uveitis and glaucoma was first reported by Joseph Beer in 1813 as arthritic iritis followed by glaucoma and blindness. In 1891 Priesley Smith proposed the first modern classification of uveitic glaucoma (UG). Specific types of UG were described by Fuchs in 1906 (heterochromic uveitis) and Posner and Schlossman in 1948 (glaucomatocyclitic crisis). ${ }^{(8)}$ In India uveitic glaucoma studies are from south India (APEDS) ${ }^{(12)}$ and Arvind eye care system and more recently from Sankara deva nethralaya in North east India. They dealt with epidemiological studies and outcome. Most studies in this field are about safe cataract surgical and glaucoma surgical outcomes.

Introduction of synthetic steroids and different paths of administrations are not devoid of complications and questionable efficacy. On this background we have undertaken this randomised prospective study in 2007-2012.

\section{Aim}

To evaluate prevalence of secondary glaucoma (SG) in uveitis with different treatment regimen

\section{Methods}

A randomised prospective hospital based study was conducted at Bokaro general hospital, asuper speciality 910 bedded hospital catering a population of more than 2 million. All the cases of uveitis coming to our hospital during 2007 and 2012 were included inthis study. Three categories of patients were enrolled :a) Patients coming directly with uveitis related complaints. B) Chronic cases on follow up, c)cross referrals from other departments like orthopaedics, paediatrics, medicine, dermatology and others. This group also includes patients referred from GPs and general ophthalmologists practicing outside. Thus cohorts fairly represent total cases of uveitis in the district population.
Besides standard eye examination, baseline IOP; Field and optic nerve head photographs were recorded. Three groups were randomised:

1. Topical steroid only

2. Systemic steroid and topical steroids,

3. Topical synthetic steroids, cycloplegic and periorbital triamcinolone injection.

Secondary glaucoma is diagnosed when IOP is more than $22 \mathrm{~mm}$ of $\mathrm{Hg}$ or $4 \mathrm{~mm}$ increase from baseline.

Corneal sensation was also tested as this is leprosy endemic area and prevalence of herpetic eye disease is high.

Fundus photograph was taken in all cases where pupil can be dilated and fluorescein angiography was done when macular oedema or unexplained visual loss is recorded.Visual field testing was done in all cases where pinhole corrected visual acuity is at least $6 / 18$ or above. Statistical analysis was done on Online software available.

\section{Statistical Analysis}

Descriptive statistics (frequencies and proportions for discrete variables) were used to determine patient characteristics and the occurrence of events, such as the need for IOP-lowering surgical procedures. Continuous descriptive statistics (mean, median, standard deviation [SD], and range) were determined for measures of VA in the logarithm of the minimum angle of resolution scale and IOP (mmHg). In addition, KaplanMeier analysis was performed to evaluate the time from implantation to surgical intervention for IOP management. The mean change in VA from preoperative to postoperative visits for implant placement was analysed using the paired $t$ test.

\section{Results}

Total 1254 cases of uveitis were registered during last five years (2007-2012) with a prevalence of 63 /lakh population. Mean incidence is 200/20lakh/year.

50 cases every year develop chronic uveitis. 
Male predominance is noticed and males are exclusively seen with comorbidankylosing spondylitis. M: F-2:1

Mean age $32.6 \mathrm{y}, 30 \%$ cases are of Juvenile category.

Secondary Glaucoma in uveitis (SG)

More than $50 \%$ cases had anterior variety with equal distribution of intermediate andposterior uveitis.10\% Cases had pan uveitis.

Mean baseline IOP at diagnosis is $17.4 \mathrm{~mm}$ whereas $21,6 \mathrm{~mm}$ hg was recorded in herpetic eye disease cases.

70 cases had baseline IOP above $22 \mathrm{~mm}$ and 12 cases had IOP $4 \mathrm{~mm}$ above the earlier recorded IOP. These 82 cases were diagnosed as secondary glaucoma (6\%), 58 cases had anterior uveitis.

550 cases were treated with topical steroids by different ophthalmologists with occasional cycloplegics.348 cases were treated with topical and oral steroids and occasional cycloplegic. Last 356 cases were treated with synthetic steroids (difluprednate), atropine and single periocular injection of triamcinolone acetate.
4 cases lost vision during treatment and 3 cases developed phthisis bulbi following cataract surgery at a tertiary care hospital.

65 cases of the secondary glaucoma were from first group and all were suffering from anterior uveitis. They need glaucoma medication during uveitis treatment and 16 cases till last follow up (2.6yrs).Posterior synechia on presentation present in $45 \%$ cases of this category.

12 cases were from second group and had mixed uveitis. Glaucoma medications had to be prescribed to them during uveitis management and to be continued in 6 cases till last follow-up.

5 cases from the last group had secondary glaucoma which subsided with minimal glaucoma therapy.

Acetazolamide $125 \mathrm{mg} / \mathrm{d}$ was given in $\mathrm{CME}$ cases.

Multi variate analysis has shown following as risk factors of secondary glaucoma in uveitis: anterior variety, comorbidity, non -atropinisation and corticosteroids and delayed diagnosis (referred cases more glaucoma).

$\begin{array}{ccccccccc}\text { Total } & \begin{array}{l}\text { Secondary } \\ \text { glaucoma at } \\ \text { presentation }\end{array} & \begin{array}{l}\text { Anti- } \\ \text { glaucoma } \\ \text { therapy } \\ \text { during } \\ \text { uveitis }\end{array} & \begin{array}{l}\text { Prolonged } \\ \text { anti glaucoma }\end{array} & \text { Group1 } & \text { Group2 } & \text { Group3 } & \begin{array}{l}\text { Statistical } \\ \text { analysis }\end{array} & \text { Comment } \\ 1254 & 82 & 82 & 22 & 65(\mathrm{n} 550) & 12(\mathrm{n} 348) & 5(\mathrm{n} 356) & \begin{array}{l}\mathrm{P}<0.05(1 \& 3) \\ \mathrm{P}>0.1(2 \& 3)\end{array} & \begin{array}{l}\text { Least SG in } \\ \mathrm{g} 3\end{array}\end{array}$

Table :2

\begin{tabular}{|l|l|l|l|l|l|l|}
\hline \multicolumn{7}{|l|}{ Secondary glaucoma and comorbidity } \\
\hline $\begin{array}{l}\text { Secondary } \\
\text { glaucoma }\end{array}$ & $\begin{array}{l}\text { Group } \\
2\end{array}$ & $\begin{array}{l}\text { Group } \\
2\end{array}$ & $\begin{array}{l}\text { Group } \\
\text { Ankylosing } \\
\text { spondylitis }\end{array}$ & $\begin{array}{l}\text { Herpetic } \\
\text { eye } \\
\text { disease }\end{array}$ & $\begin{array}{l}\text { Metabolic } \\
\text { disorders }\end{array}$ \\
\hline $\begin{array}{l}\text { No of } \\
\text { cases }\end{array}$ & 65 & 12 & 5 & 12 & 8 & 6 \\
\hline $\begin{array}{l}\text { Prolonged } \\
\text { glaucoma }\end{array}$ & 16 & 6 & 0 & 6 & 8 & 2 \\
\hline $\begin{array}{l}\text { Posterior } \\
\text { synechia }\end{array}$ & 28 & 4 & 1 & 2 & 4 & 6 \\
\hline $\begin{array}{l}\text { Anterior } \\
\text { uveitis }\end{array}$ & 48 & 8 & 9 & 6 & 4 & 2 \\
\hline Comorbidity significantly (p<0.05) increases secondary glaucoma risks \\
\hline
\end{tabular}




\section{Discussion}

Prevalence is 6\% which is less compared to US data, this is probably because our data includes cases over five years. Most studies found UG equally distributed among anterior and posterior uveitis.70\% of UG in our study is associated with anterior uveitis which is also the case in single centre study in US ${ }^{(9)}$. This can be explained by associated cases of ankylosing spondylitis, herpetic eye disease and juvenile arthritis. Younger age predisposes more to glaucoma.

The treatment of uveitis with corticosteroids results in elevated IOP in up to one-third of patients. 9 although corticosteroids have proven to be effective in reducing inflammation, prolonged administration can result in elevated IOP by decreasing aqueous outflow. Secondary ocular hypertension from corticosteroid administration is dependent on the dose, the chemical structure of the corticosteroid compound, the frequency and route of delivery, the duration of treatment, and the patient's susceptibility to steroid response ("steroid responders"). Clinically, a corticosteroid response usually develops 2 to 6 weeks after initiating therapy, but may occur at any time. It is often difficult to distinguish between the side effects of the corticosteroids and the underlying inflammation. Only about 5\% of the normal population demonstrates corticosteroid responsiveness, (10) but with impaired conventional outflow seen during intraocular inflammation, the corticosteroid response rate rises significantly. The risk factors of being a steroid responder are primary open-angle glaucoma, familial history of glaucoma, rheumatoid arthritis, extremes of age (children and the elderly), and diabetes. Children are especially susceptible to an IOP increase secondary to steroids. ${ }^{(6)}$.Corticosteroids have been reported to cause biochemical and morphological changes in the trabecular meshwork, increasing resistance to aqueous outflow, and several theories have been proposed to explain this phenomenon, including accumulation of glycosaminoglycan in the trabecular meshwork, inhibition of phagocytosis by trabecular endothelial cells, and inhibition of synthesis of certain prostaglandins. ${ }^{(7)}$

\section{Conclusion}

1 in 167 population has uveitis in Bokaro district, 1 in 8 uveitic patients have secondary glaucoma which more predominant in patients with comorbidity who are not atropinised from beginning. This complication is the cause of visual loss in 1 out of 80 uveitis patients and can be prevented in most instances.

\section{References}

1. Allingham RR, Damji K, Freedman $S$, et al. Steroid induced glaucoma, in Allingham RR, Damji K, Freedman S, et al (eds). Shields Textbook of Glaucoma. Baltimore, MD,

2. Allingham RR. Glaucoma due to intraocular inflammation,in Epstein DL, Schuman JS (eds). Chandler and Grant's glaucoma. Baltimore, MD, Williams and Willkins; ed 4. 1997, pp 376—94

3. Boyle JW, Netland PA, Salim S, et al. Uveitic glaucoma: pathophysiology and management. EyeNet. 2008;12:39—41

4. Heinz C, Koch JM, Zurek-Imhoff B, et al. Prevalence of uveitic secondary glaucoma and success of nonsurgical treatment in adults and children in a tertiary referral center. OculImmunolInflamm. 2009; 17:243-8

5. Herbert HM, Viswanathan A, Jackson H, et al. Risk factors for elevated intraocular pressure in uveitis. $\mathrm{J}$ Glaucoma, 2004;13:96-9

6. Sallam A, Sheth HG, Habot-Wilner Z, et al. Outcome of raised intraocular pressure in uveitic eyes with and without a corticosteroid- induced hypertensive response. Am J Ophthalmol. 2009; 148:207-13

7. Sijssens KM, Rothova A, Berendschot TT, et al. Ocular hypertension and secondary 
glaucoma in children with uveitis.

Ophthalmology. 2006;113:853—9

8. Herdnon L Jr. Glaucoma, uveitic treatment, and management.http://emedicine.medscape.com/article/1206838overview. Accession date 6 oct 2013.

9. Salim S, Boyle JW, Netland PA. Pathophysiology and management uveitic glaucoma. Ophthalmic Pearls: Glaucoma (Sep 2008).http://www.aao.org/publications/eyenet/200809/pearls.cfm.

10. Sana S. Siddique,Ana M. Suelves, UjwalaBaheti, and C. Stephen Foster.Glaucoma and Uveitis. Surv Ophthalmol 58:1--10, 2013.

11. Bodaghi B, Cassoux N, Wechsler B, et al. Chronic severe uveitis: etiology and visual outcome in 927 patients from a single center. Edicine (Baltimore). 2001;80:26370

12. L Dondona ,RDondona et al.Population based assessment of uveitis in an urban population in southern India.Br J Ophthalmol 2000,84:706-709 